\title{
Neuregulin 1 in schizophrenia: out of Iceland
}

\author{
Molecular Psychiatry (2003) 8, 639-640. doi:10.1038/ \\ sj.mp.4001384
}

Schizophrenia is a disease that has proven difficult for scientists to crack. It is characterized by alterations in the content of consciousness and in spite of the fact that we know much more about the function of the brain today than we did a few years back, we know precious little about how it works as an organ of consciousness. Schizophrenia is a disease without a clear anatomic lesion or a known causative agent. It has, however, a genetic component; there is an inherited predisposition to the development of schizophrenia. ${ }^{1,2}$ Schizophrenia is a disease that highlights the advantages of the human genetics approach to the study of human disease: we know little about the basic function that is perturbed by the disease and it affects an organ that is difficult to biopsy. Therefore, it has proven difficult to advance our understanding of the disease by putting together hypotheses that are subsequently tested. The genetics approach, however, is model independent and allows for the isolation of a disease gene independent of preconceived notions about its pathogenesis. Once you have the gene in hand you can put the protein it encodes, into the context of biological pathways that are already known or use it as a tag for a new pathway. In either case, this defines a key pathway that leads to an understanding of how the disease happens or provides an excellent position from which to construct a hypothesis on the topic. The human genetics approach to common diseases has been difficult, and until recently, it has proven hard to isolate genes that contribute to the pathogenesis of common diseases; schizophrenia has been no exception to that. However, recent publications have reported the isolation of three schizophrenia canditate genes: the dysbindin gene ${ }^{3}$ the gene encoding G72, ${ }^{4}$ and the Neuregulin 1 (NRG1) gene. ${ }^{5}$ It is of interest here that all the three may play a part in the glutamatergic system.

Stefánsson et $a l^{5}$ described the isolation of a candidate for a schizophrenia gene from a locus on chromosome 8p22-p11 that has shown up in several genomewide scans for schizophrenia genes. ${ }^{6-9}$ The gene encodes members of the neuregulin family ${ }^{10}$ of proteins, NRG1, that may influence both synaptogenesis and synaptic plasticity and in that invites the possibility that the gene may hold, in part, not only the secret to the genetic predisposition to schizophrenia, but also the mechanism whereby the environment contributes to the pathogenesis of the disease. The environment influences the brain in many ways, and the one that is most specific to the brain is through the experience of the beholder; one of the ways in which the brain responds to experience is through synaptic remodeling that may be influenced by NRG1. Therefore, the NRG1 gene may shed light on how both nature and nurture contribute to the pathogenesis of schizophrenia.

How conclusive is the evidence supporting a role for the NRG1 gene in schizophrenia? The original report by Stefansson et $a l^{5}$ was based on work done with the Icelandic population that showed highly significant association between a seven-marker haplotype covering the $5^{\prime}$ end of the NRG1 gene and schizophrenia, but it did not describe a causative mutation in spite of a substantial effort to find one. The haplotype confers a relative risk of about 2. A second report by Stefansson et $a l^{11}$ described a significant association between schizophrenia and the same alleles of the seven-marker haplotype that tracks schizophrenia in Iceland in a cohort of schizophrenics from Scotland, conferring a similar relative risk; still no pathogenic mutation was described. Two articles in Molecular Psychiatry report replications of NRG1 association with schizophrenia, one by Williams et $a l^{12}$ working with a group of Caucasians born in the UK or Ireland (published in the May issue) and the other by Yang et $a l^{13}$ with Chinese Hans (published in this issue). Williams et $a l^{12}$ report a significant association to schizophrenia of a three-marker core haplotype covering a region at the $5^{\prime}$ end of the gene described by Stefansson et al; it confers a smaller relative risk in their population, but the actual relative risks must await discovery of the mutation underlying the haplotypes. Yang et $\mathrm{al}^{13}$ describe both, significant association of each of three SNPs within the NRG1 gene to schizophrenia, and the association of a haplotype consisting of the three SNPs. This haplotype reaches much deeper into the gene than the haplotype described by Stefánsson et al, or all the way into the fifth intron. These two reports constitute additional evidence in support of a role for NRG1 in conferring susceptibility to schizophrenia. It is not difficult to live with the fact that the markers and the haplotypes that display the strongest association to the disease are not exactly the same in all populations; it is not unexpected that mutations in different populations are to be found on the background of different haplotypes. Furthermore, it is also possible that there is a diversity of mutations in the NRG1 gene that are responsible for schizophrenia.

One concern that is frequently raised when a disease gene is mapped or isolated in a small, relatively homogeneous population is that the gene may not be relevant to the disease in question among the larger and more heterogeneous nations. This assumes that the pathogenesis of the disease would be different in small populations than in large ones. 
640

There is little evidence supporting this notion, but mounting evidence showing that the same genes play the dominant role in the genetics of the common diseases both in small population isolates and among large nations. The story of NRG1 provides an example of a gene that was isolated in Iceland and has been shown to be relevant to schizophrenia in populations as diverse as the Irish, Scottish, English, and Chinese. It is, however, given that the mutational diversity in the disease genes is going to be greater among the large, heterogeneous populations; in that lies a part of the advantage of working on the isolation of disease genes among the smaller more homogeneous populations.

In summary, schizophrenia is beginning to give ground to the power of modern genetics and the plan is to turn the genes we have isolated into better ways to treat and prevent this mind-altering disease. Our patients and their families empowered us to isolate the genes; we owe it to them to succeed.
1 Cardno AG et al. Arch Gen Psychiatry 1999; 56: 162-168.

2 Tsuang MT et al. Br J Psychiatry Suppl 2001; 40: s18-s24.

3 Straub RE et al. Am J Hum Genet 2002; 71: 337-348.

4 Chumakov I et al. Proc Natl Acad Sci USA 2002; 99: 1367513680.

5 Stefansson H et al. Am J Hum Genet 2002; 71: 877-892.

6 Pulver AE et al. Am J Med Genet 1995; 60: 252-260.

7 Kendler KS et al. Am J Psychiatry 1996; 153: 1534-1540.

8 Blouin JL et al. Nat Genet 1998; 20: 70-73.

9 Brzustowicz LM et al. Am J Hum Genet 1999; 65: 10961103.

10 Falls DL. Exp Cell Res 2003; 284: 14-30.

11 Stefansson H et al. Am J Hum Genet 2003; 72(1): 83-87.

12 Williams N et al. Mol Psychiatry 2003; 8: 485-487.

13 Yang J et al. Mol Psychiatry 2003; 8: 706-709.

H Stefánsson, TE Thorgeirsson, JR Gulcher and $\mathrm{K}$ Stefánsson

Decode Genetics, Sturlugata 8, Reykjavik, Iceland E-mail: kstefans@decode.is 